\title{
NADPH-diaphorase is Colocalized with Nitric Oxide Synthase and Vasoactive Intestinal Polypeptide in Rat Pancreatic Neurons in Culture
}

\author{
S. S. W. TAY* and E. W. MouleS \\ Department of Anatomy and Developmental Biology, and Centre for Neuroscience, University College London, \\ London, United Kingdom
}

Received March 15, 1994

\begin{abstract}
Summary. NADPH-diaphorase activity together with nitric oxide synthase- and vasoactive intestinal polypeptide-immunoreactivities were examined in the neurons of the rat pancreas in culture. Nitric oxide synthase (NOS)- and vasoactive intestinal polypeptide (VIP)immunoreactivities were localized in a subpopulation of neurons which were also NADPH-diaphorase positive. All neurons expressing colocalized activities for NOS/ VIP and NADPH-diaphorase were solitary cells in culture. Each of these double-labelled neurons was characterized by a round or oval cell body, with short and long processes emanating from it. Some of these processes traversed several micrometres before terminating on the exocrine acinar and endocrine cells. The present study provides evidence that nitric oxide may act as a regulatory agent in the inhibitory neural control of the secretory functions in the pancreas, thereby maintaining the milieu interieur of the organism.
\end{abstract}

Recent evidence suggests that nitric oxide (NO) is not only responsible for endothelium-derived relaxing factor activity but also participates as a neuronal messenger molecule in both the central and peripheral nervous system (DAWSON et al., 1991; SNYDER and BREDT, 1991). In the autonomic nervous system, pharmacological and electrophysiological evidence suggests that NO is an important mediator of some non-adrenergic, non-cholinergic (NANC) inhibitory responses (RAND, 1992). Subpopulations of neurons which express nitric oxide synthase (NOS) activity have been localized in the rat enteric ganglia (BREDT, HWANG and SNYDER, 1990; DAWSON et al., 1991;
BELAI et al., 1992), guinea-pig enteric ganglia (CosTA et al., 1992; SAFFreY et al., 1992; YounG et al., 1992), guinea-pig cardiac ganglia (HASSALL et al., 1992) and rat adrenal gland (AFEWORK et al., 1992). In all these autonomic ganglia, NOS-immunoreactivity has been found to be colocalized with NADPH-diaphorase activity. Recently, the mediation of insulin secretion from pancreatic $\beta$ cells by L-arginine-derived NO has also been reported (SCHMIDT et al., 1992). Moreover, $\mathrm{NADPH}$-diaphorase and vasoactive intestinal polypeptide (VIP) have been colocalized in the neurons of gall bladder, and it has been postulated that they are intrinsic inhibitory neurons (TALMAGE and MAWE, 1993). It is well-known that VIPergic neurons are present in the pancreas, but they have yet to be demonstrated to co-exist with NADPH-diaphorase in culture. The aim of the present investigation was to localize the co-existence of NADPH-diaphorase with NOS and VIP in the neurons of the rat pancreas in culture.

\section{MATERIALS AND METHODS}

Cultures of the pancreatic neurons were prepared as described previously for cardiac neurons (HASSALL and BURNSTOCK, 1986). Two-week-old rats were sacrificed with a blow to the head, and the whole pancreas was excised by careful dissection in aseptic conditions. The isolated pancreas was then subjected to trypsin and collagenase treatments before being injected into modified Rose chambers. Cultures were

\footnotetext{
*Present address: Department of Anatomy, National University of Singapore, 10 Kent Ridge Crescent, Singapore 0511, Republic of Singapore
} 
allowed to grow for 6-8 days in vitro, in medium 199 (Life Technologies Ltd., Glasgow, U.K.) supplemented with $10 \%$ foetal calf serum, $6 \mathrm{mg} / \mathrm{ml}$ glucose and 1000 units of penicillin. After fixation with $4 \%$ formalin in phosphate buffered saline (PBS, $\mathrm{pH}$ 7.3), the cultures were rinsed 3 times in PBS, permeabilised in PBS containing $0.1 \%$ Triton X-100, and then rinsed 2 times in PBS before staining.

\section{NADPH-diaphorase histochemistry}

Culture preparations were rinsed in $0.1 \mathrm{M}$ TRIS buffer ( $\mathrm{pH}$ 7.6) and then incubated for $1 \mathrm{~h}$ in the dark at room temperature $\left(20^{\circ} \mathrm{C}\right)$ in $0.1 \mathrm{M}$ TRIS containing $0.2 \mathrm{mg} / \mathrm{ml}$ nitroblue tetrazolium, $2.7 \mathrm{mg} / \mathrm{ml} \mathrm{L}$-maleic acid, $1 \mathrm{mg} / \mathrm{ml} \quad \beta$-NADPH and $10 \mu \mathrm{l} / \mathrm{ml}$ of $0.1 \%$ Triton X-100 (all from Sigma Ltd., Poole, U.K.). The reaction was monitored periodically using a dissecting microscope, and stopped by rinsing in excess TRIS buffer. Some of these culture preparations were washed in 2 changes of PBS and mounted in Citifluor mountant (City University, London, U.K.) before being viewed with bright field and phase contrast optics using a Carl Zeiss Axioplan Universal microscope (Germany). Controls were performed with the omission of the enzyme substrate $\beta$-NADPH from the incubating medium. Freshly stained unmounted culture preparations from the same lot were then used for immunohistochemical staining in doublelabelling experiments.

\section{Immunohistochemistry}

Localization of neurons in the pancreatic cultures was obtained by immunostaining with protein gene product 9.5 (PGP 9.5, Ultraclone Ltd., Isle of Wight, U.K.). NOS in neurons was localized using specific antisera (6761-9 and 6763-5) raised against NOS purified from the rat cerebellum (courtesy of $U$. FORSTERMANN). Other studies in our laboratory have shown that these antisera give specific labelling for NOS in other autonomic ganglia (BELAI et al., 1992; HASSALL et al., 1992; SAFFrEY et al., 1992). For double labelling, NADPH-diaphorase staining was carried out prior to immunolabelling. Fixed cultures were incubated in the primary antiserum (anti-PGP $9.5,1: 3000$; anti-NOS, $1: 1000$; anti-VIP, $1: 1000$ ) overnight at room temperature in PBS containing $0.01 \%$ lysine, $0.01 \%$ bovine serum albumin, $0.1 \%$ Triton $\mathrm{X}-100$ and $0.1 \%$ sodium azide (Sigma Ltd. Poole, U. K.). Visualization of the binding of the primary antiserum was achieved using a biotinylated second layer (donkey anti-rabbit IgG, $1: 250$ ), followed by streptavidin fluorescein $(1: 100)$ (all from Amersham Ltd., Aylesbury, U.K.) and then washed 2 times in PBS before being mounted in Citifluor mountant.

\section{RESULTS}

In tissue culture preparations, the pancreatic neurons of the rat occurred as single cells (Fig. 1). Most of these neurons have long as well as short varicose processes. The varicose processes were frequently observed to terminate on the exocrine acinar cells. A few processes were also observed to terminate on the endocrine cells. Very often, some of these long processes were ensheathed by connective tissue.

NADPH-diaphorase labelled neurons were commonly observed in cultures of the rat pancreas. Both heavily and moderately labelled neurons were observed. No histochemical reaction product was observed in the neuronal structures in control preparations incubated in the absence of $\beta$-NADPH.

Employing double-labelling with antiserum to the neuronal marker PGP 9.5 showed most of the neurons to be NADPH-diaphorase positive (Fig. 1a, b). Each of these double-labelled neurons was characterized by a round to oval cell body containing a rounded nucleus and several processes emanating from it. NADPH-diaphorase reaction product was localized in the cytoplasm and processes but not in the nucleus (Fig. 1b). The proximal processes of some NADPH-diaphorase positive neurons could be traced for several micrometres, insinuating amongst the exocrine acinar and endocrine cells. Very often, some of the distal processes of the neurons were labelled for both PGP 9.5 and NADPH-diaphorase. Most of the distal processes finally terminated on the exocrine acinar cells in culture. In all double-labelling experiments, NADPH-diaphorase histochemical staining was performed prior to immunolabelling, as the latter tended to mask the diaphorase activity (HASSAll et al., 1992; SAFFrEY et al., 1992).

NOS-immunoreactivity was localized in a subpopulation of neurons in the rat pancreas in culture. Each of the NOS positive neurons was characterized by a round to oval cell body, with short and long processes emanating from it (Fig. 1c). Some of these prcesses appeared to be closely associated with the exocrine acinar and endocrine cells. Most of these processes finally terminated on the exocrine acinar cells in culture. Long, varicose processes often meandered amongst the other cell types and traversed distances of several micrometres. In most cultures, neurons which were double-labelled with NOS and NADPH-diaphorase still showed strong immunofluorescence (Fig. 1c, d), at least in the cell bodies. However, in some neurons, prior labelling for NADPH-diaphorase appeared to reduce the intensity of the immunolabelling for NOS. Close examination 

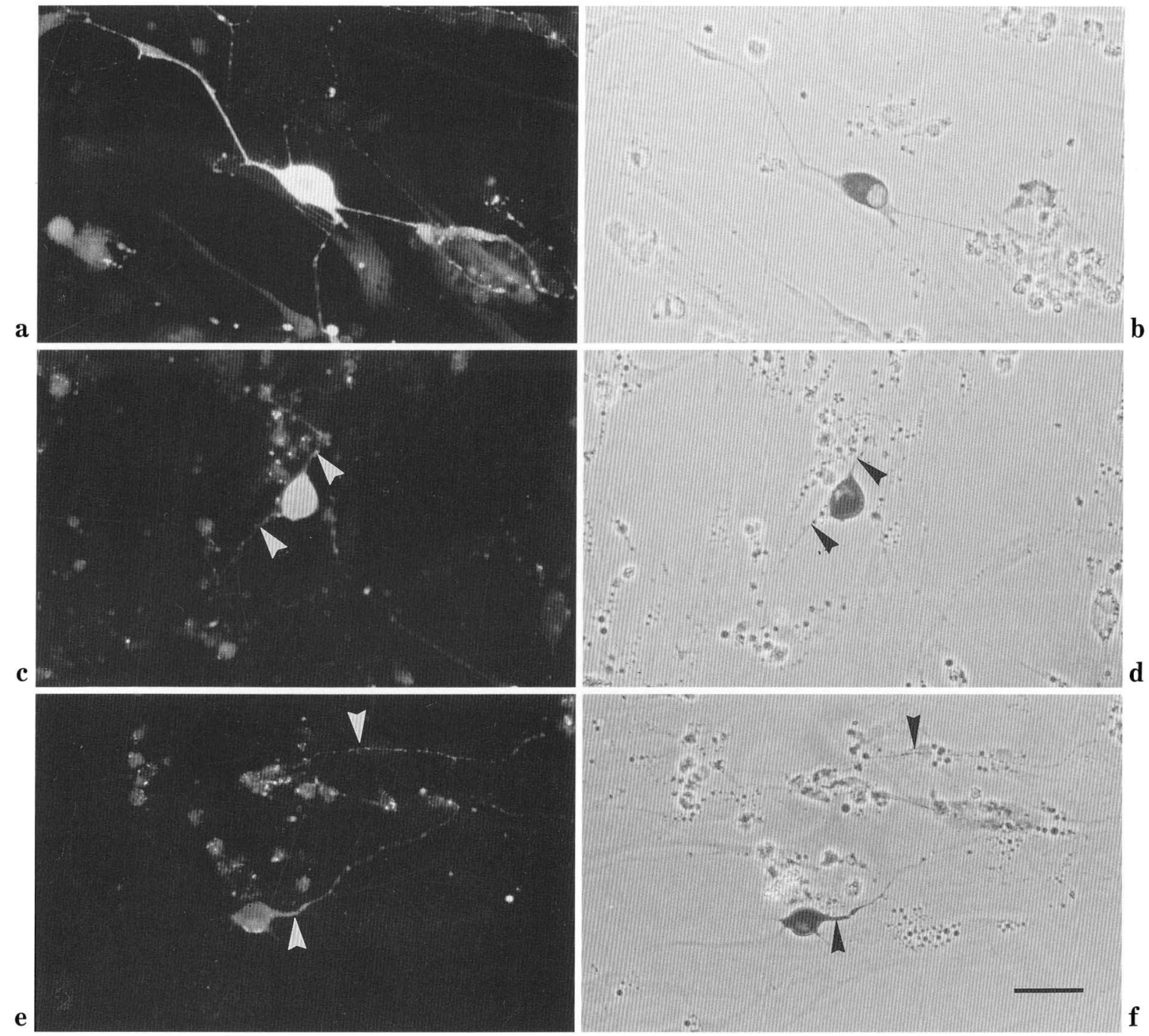

Fig. 1 a and b. Fluorescence and phase contrast micrographs showing a solitary pancreatic neuron with PGP 9.5 and NADPH-diaphorase labelling respectively. Note the double-labelled processes emanating from the cell body and their close association with the exocrine acinar and endocrine cells in culture. $\mathbf{c}$ and $\mathbf{d}$. Coexistence of NOS immunoreactivity with NADPH-diaphorase activity in a solitary pancreatic neuron grown for 6 days in culture. Note the light labelling of the neuronal processes (arrowheads) for both NOS-immunoreactivity (c) and NADPH-diaphorase activity (d). e and f. A solitary neuron demonstrating VIP-immunoreactivity and NADPH-diaphorase activity. Note that the double-labelling involves the cell body together with its proximal and distal processes (arrowheads). Also observe the dim fluorescence for VIP localization resulting from the quenching effect of the prior staining of the same neuron for NADPH-diaphorase activity. Scale bar represents $46 \mu \mathrm{m}$ for all micrographs. 
of cultures by fluorescence, bright field and phase contrast microscopy revealed that the majority of neurons in cultures were both NADPH-diaphorase positive and NOS-immunoreactive. However, a few of the NADPH-diaphorase positive neurons did not exhibit NOS-immunoreactivity.

VIP-immunoreactivity was also colocalized with NADPH-diaphorase activity in some of the cultured neurons (Fig. 1e, f). These neurons were solitary multipolar neurons. Each neuron was characterized by a round to oval cell body with short and long processes emanating from it. The staining for VIPimmunoreactivity in some of the double labelled neurons appeared dim, due to the prior stianing of the same neurons for NADPH-diaphorase activity (Fig. 1 e, f). The labelling for NADPH-diaphorase was concentrated mainly in the cell body and its processes, but not within its nucleus. Most of the varicose processes traversed distances of several micrometres and finally terminated on the exocrine acinar cells; however, a few processes also terminated on the endocrine cells of the pancreas in culture.

\section{DISCUSSION}

The results of the double-labelling experiments and the close similarity between the proportions and intensity of the labelling of NOS-immunoreactive and $\mathrm{NADPH}$-diaphorase positive pancreatic neurons in cultures indicate that the two enzyme activities are co-expressed by the labelled cells, thereby supporting the view that they are part of a single molecule (BREDT, HWANG and SNYDER, 1990; DAwSON et al., 1991; HoPE et al., 1991). In all the pancreatic neurons studied, NOS-immunoreactivity appears to be closely related to the NADPH-diaphorase activity. However, not all NADPH-diaphorase positive neurons demonstrate NOS-immunoreactivity. This may be correlated to the fact that NADPH-diaphorase may occur as different isoforms (FORSTERMANN et al., 1991; MONCADA, PALMER and HIGGS, 1991; SNYDER, 1992).

In view of the recent findings that a subset of vasoactive intestinal polypeptide (VIP)- and neuropeptide $\mathrm{Y}(\mathrm{NPY})$-immunoreactive pancreatic neurons contain NADPH-diaphorase, while bombesin-immunoreactive pancreatic neurons do not (KIRCHGESSNER, LIU and GERSHON, 1993), the NOS/VIP-immunoreactive and NADPH-diaphorase positive pancreatic neurons described here may also express NPY activity in culture. It therefore appears that NO may relate in complex patterns with a variety of neurochemicals in the pancreatic neurons. Some of these pancreatic neurons have been observed to lie in close association with both exocrine and endocrine cells in situ and in culture in the present study. The observation that some of the NOS-immunoreactive neuronal processes terminate on the exocrine acinar and endocrine cells provides morphological support for neuronal derived NO influence on their secretory functions, thereby influencing the milieu interieur of the pancreas.

An important new finding in this report is that some of the cultured pancreatic neurons are immunoreactive for VIP and that these neurons also show NADPH-diaphorase activity. VIP has been shown to be present in the inhibitory neurons of the gut (D'Amoto, Curro and Montuschi, 1992; Huizinga, TOMLINSON and PINTIN-QUEZADA, 1992) and has been found to be released to relax the gut via vagal stimulation (SCHAFFALITZKY DE MUCKADELL, FAHRENKRUG and HoLST, 1977). The present finding of the coexistence of NADPH-diaphorase with NOS and VIP in a subset of neurons in the rat pancreas in culture further substantiates the contention that these intrinsic neurons are inhibitory neurons, as has been proposed for VIP-ergic neurons in the gall bladder of the guinea pig (TALMAGE and MAWE, 1993). In the present study, the localization of NADPH-diaphorase activity in VIP-immunoreacitive neurons suggests that NO may act as a modulator of VIP-ergic neurotransmission (see SANDERS and WARD, 1992) in the pancreatic neurons. SHIMOSEGAWA et al. (1993) have suggested that the possible coexpression and coproduction of NO and VIP may not be specific to intrinsic neurons of the mammalian pancreas but instead represent a general rule for the intrinsic neurons of the digestive system. In the gut, both VIP and NO have been shown to relax smooth muscle, and the effects of these compounds may be synergistic (D'AMATO, CURRO and Montuschi, 1992; Huizinga, TomLINSON and PintinQUEZADA, 1992). It remains to be established whether NO and VIP are co-released in pancreatic neurons as well as whether the actions of these compounds are synergistic in their effects on the exocrine acinar and endocrine cells of the pancreas.

Acknowledgements. This work was supported in part by the Wellcome Trust. S. S. W. TAY is extremely grateful to Professor G. BuRNSTOCK for providing the unique opportunity to learn cell culture at University College London, England. The editorial asistance of Dr. D. CHRISTIE is gratefully acknowledged. We are grateful to Miss. P. F. CHENG for typing the final manuscript. 


\section{REFERENCES}

Afework, M., A. Tomlinson, A. Belai and G. Burnstock: Colocalization of nitric oxide synthase and NADPHdiaphorase in rat adrenal gland. NeuroReport 3: 389396 (1992).

Belai, A., H. H. H. W. Schmidt, C. H. V. HoYle, C. J. S. Hassall, M. J. Saffrey, J. Moss, U. Forstermann, F. Murad and G. Burnstock: Colocalization of nitric oxide synthase and NADPH-diaphorase in the myenteric plexus of the rat gut. Neurosci. Lett. 143: 60-64 (1992).

Bredt, D. S., P. M. HWANG and S. H. SNyder: Localization of nitric oxide synthase indicating a neural role for nitric oxide. Nature 347: 768-770 (1990).

Costa, M., J. B. Furness, S. Pompolo, S. J. H. Brookes, J. C. Bonnstein, D. S. Bredt and S. H. SNyder: Projections and chemical coding of neurons with immunoreactivity for nitric oxide synthase in the guineapig small intestine. Neurosci. Lett. 148: 121-125 (1992).

D’Amato, M., D. Curro and P. Montuschi: Evidence for dual components in the non-adrenergic noncholinergic relaxation in the rat gastric fundus: role of endogeneous nitric oxide and vasoactive intestinal polypeptide. J. Auton. Nerv. Syst. 37: 175-186 (1992).

Dawson, T. M., D. S. Bredt, M. Foutachi, P. M. Hwang and S. H. SNYDER: Nitric oxide synthase and neuronal NADPH-diaphorase are identical in brain and peripheral tissues. Proc. Nat. Acad. Sci, USA 88: 7797-7801 (1991).

Forstermann, U., H. H. H. W. Schmidt, J. S. Pollock, H. Sheng, J. A. Mitchell, T. D. W ARner, M. Nakane and F. MURAD: Isoforms of nitric oxide synthase: characterization and purification from different cell types. Biochem. Pharmacol. 42: 1849-1857 (1991).

Hassall, C. J. S. and G. BuRnstock: Intrinsic neurones and associated cells of the guinea-pig heart in culture. Brain Res. 364: 102-113 (1986).

Hassall, C. J. S., M. J. Saffrey, A. Belai, C. H. V. Hoyle, E. W. Moules, J. Moss, H. H. H. W. Schmidt, F. MuRAd and G. BuRnstock: Nitric oxide synthase immunoreactivity and NADPH-diaphorase activity in a subpopulation of intrinsic neurones of the guinea-pig heart. Neurosci. Lett. 143: 65-68 (1992).

Hope, B. T., G. J. MichaEL, K. M. KNigge and S. R. VINCENT: Neuronal NADPH-diaphorase is a nitric oxide synthase. Proc. Nat. Acad. Sci. USA 88: 28112814 (1991).

Huizinga, J. D., J. Tomlinson and J. Pintin-Quezada: Involvement of nitric oxide in nerve-mediated inhibition and action of vasoactive intestinal peptide in colonic smooth muscle. J. Pharmacol. Exp. Therap. 260: G1138-G1142 (1992).
Kirchgessner, A. L., M. T. LiU and M. D. Gershon: NADPH-diaphorase (nitric oxide synthase) in the enteropancreatic innervation. Anat. Rec. Suppl. 1: 72 (1993).

Moncada, S., R. M. J. Palmer and E. A. HigGs: Nitric oxide: Physiology, pathophysiology and pharmacology. Pharmacol. Rev. 43: 109-142 (1991).

RAND, M. J.: Nitrergic transmission: Nitric oxide as a mediator of non-adrenergic, non-cholinergic neuro-effector transmission. Clin. Exp. Pharmacol. Physiol. 19: 147169 (1992).

Saffrey, M. J., C. J. S. Hassall, C. H. V. Hoyle, A. Belai, J. Moss, H. H. H. W. Schmidt, U. ForstermanN, F. MURAD and G. BuRnstock: Colocalization of nitric oxide synthase and NADPH-diaphorase in cultured myenteric neurones. NeuroReport 3: 333-336 (1992).

SANDERS, K. M. and S. M. WARD: Nitric oxide as a mediator of nonadrenegic noncholinergic neurotransmission. Amer. J. Physiol. 262: G379-G392 (1992).

Schaffalitzky de Muckadell, O. B., J. Fahrenkrug and J. J. HoLST: Release of vasoactive intestinal peptide (VIP) by electric stimulation of the vagal nerves. Gastroenterology 72: 373-375 (1977).

SchmidT, H. H. H. W., T. D. W ARNER, K. IShII, H. SHENG and F. MURAD: Insulin secretion from pancreatic $\beta$ cells caused by L-arginine-derived nitrogen oxides. Science 255: 721-723 (1992).

Shimosegawa, T., T. Abe, A. Satoh, R. Abe, Y. KikUChi, M. KoIzUMI and T. Toyota: NADPH-diaphorase activity in neurons of the mammalian pancreas: Coexpression with vasoactive intestinal polypeptide. Gastroenterology 105: 999-1008 (1993).

SNYDER, S. H.: Nitric oxide and neurons. Curr. Opinion Neurobiol. 2: 323-327 (1992).

SNYDER, S. H. and D. S. BREDT: Nitric oxide as neuronal messenger. Trends Pharmacol. Sci. 12: 125-128 (1991).

TAlmage, E. K. and G. M. MAWE: NADPH-diaphorase and VIP are co-localized in neurons of gallbladder ganglia. J. Auton. Nerv. Syst. 43: 83-90 (1993).

Young, H. M., J. B. Furness, C. W. R. ShutTleworth, D. S. BREDT and S. H. SNYDER: Colocalization of nitric oxide synthase immunoreactivity and NADPH-diaphorase staining in neurons of the guinea-pig intestine. Histochemistry 97 : 375-378 (1992).
Dr. S. S. W. TAY

Department of Anatomy

National University of Singapore

10 Kent Ridge Crescent

Singapore 0511

Republic of Singapore 